Дмітрієва Ніколь Субханівна студент магістратури кафедри олімпійського та професійного спорту, факультету фізичного виховання, спорту i здоров'я, Національного педагогічного університету імені М. П. Драгоманова, вул. Пирогова, 9, м. Київ, 01601, тел.: (067) 765-61-99, e-mail: nikol.s.dmitriieva@gmail.com, nikolestern@ukr.net, https://orcid.org/00000001-6492-3371

\title{
ФОРМУВАННЯ СТИЛЮ ПРОФЕСІЙНОЇ ДІЯЛЬНОСТІ МАЙБУТНЬОГО ВЧИТЕЛЯ ФІЗИЧНОЇ КУЛЬТУРИ
}

Анотація. Метою статті є дослідження особливостей формування стилю професійної діяльності майбутнього вчителя фізичної культури. Розглянувши різноманітні психологічні та педагогічні підходи до розуміння феномену «індивідуальний і професійний стиль педагогічної діяльності», 3 огляду на специфіку професійної діяльності вчителя фізичної культури, були віднесені до області стилю такі характеристики педагогічної діяльності, як висока вмотивованість самостійної творчої діяльності; індивідуальне особливе розуміння аспектів педагогічної роботи; ступінь внесення в свою роботу особистісного начала; прагнення до саморозвитку та самовдосконалення в професійній діяльності; задоволення потреби в професійній самореалізації. Успішність здійснення педагогічної діяльності передбачає оволодіння необхідними професійними компетенціями, що дозволяють реалізовувати структурні компоненти діяльності вчителя фізичної культури. Професійнокогнітивний компонент - когнітивна компетенція характеризується знанням вікових i психологічних особливостей розвитку школяра в контексті формування фізичної культури особистості. Предметно-інструментальний компонент - предметно-інструментальна компетенція визначається знанням принципів гуманної педагогіки i проявляється в умінні вибирати i використовувати сучасні оздоровчі технології, виділити мета, розробляти зміст конкретних занять, володіння педагогічною рефлексією. Здоров'яформуючий компонент - здоровёяформуюча компетенція проявляється в конструктивних уміннях створювати і коректувати здоровьесохранную освітне середовище; вміння направляти особистісний розвиток школяра; використовувати індивідуальний підхід. Професійно комунікативний компонент комунікативна компетенція передбачає розвинену культуру спілкування, здатність до швидкого реагування на виникає ситуацію, володіння різними способами взаємодії. Професійно-креативний компонент - креативна компетенція виражається в розвиненому творчому мисленні, моторнотворчому самовираженні i характеризується здатністю знаходити i 
використовувати різні варіанти вирішення педагогічних завдань; здатність вільно переходити від однієї проблеми до іншої; приймати ефективні, нестандартні, неординарні рішення.

Ключові слова: вчитель фізичної культури, стиль професійної діяльності, професійна підготовка, педагогічна освіта, професійна підготовка вчителів фізичної культури.

Dmitriieva Nikol Subkhanivna Master's student Department of Olympic and Professional Sports, Faculty of Physical Education, Sports and Health, National Pedagogical Dragomanov University, Pyrohova St., 9, Kyiv, 01601, tel.: (067) 76561-99, e-mail: nikol.s.dmitriieva@gmail.com, nikolestern@ukr.net, https://orcid.org/0000-0001-6492-3371

\section{FORMATION OF STYLE OF PROFESSIONAL ACTIVITY OF THE FUTURE TEACHER OF PHYSICAL CULTURE}

Abstract. The purpose of the article is to study the features of the formation of the style of professional activity of the future teacher of physical culture. Having considered various psychological and pedagogical approaches to understanding the phenomenon of "individual and professional style of pedagogical activity", given the specifics of professional activity of physical education teachers, such characteristics of pedagogical activity as high motivation of independent creative activity were attributed to style; individual special understanding of aspects of pedagogical work; the degree of introduction of personal principles in their work; striving for selfdevelopment and self-improvement in professional activity; meeting the need for professional self-realization. The success of pedagogical activities involves mastering the necessary professional competencies that allow you to implement the structural components of the physical education teacher. Professional-cognitive component - cognitive competence is characterized by knowledge of age and psychological characteristics of the student in the context of the formation of physical culture of the individual. Subject-instrumental component - subjectinstrumental competence is determined by knowledge of the principles of humane pedagogy and is manifested in the ability to choose and use modern health technologies, identify goals, develop the content of specific classes, mastery of pedagogical reflection. Health-forming component - health-forming competence is manifested in constructive skills to create and adjust a healthy educational environment; the ability to guide the personal development of the student; use an individual approach. Professionally communicative component - communicative competence involves a developed culture of communication, the ability to respond quickly to emerging situations, mastery of different ways of interaction. Professional-creative component - creative competence is expressed in developed creative thinking, motor-creative self-expression and is characterized by the ability to find and use different solutions to pedagogical problems; the ability to move freely from one problem to another; make effective, non-standard, extraordinary decisions. 
Keywords: physical education teacher, style of professional activity, professional training, pedagogical education, professional training of physical education teachers.

Постановка проблеми. На сучасному етапі соціального розвитку суспільства рівень фізичної культури особистості багато в чому визначає ступінь адаптації індивіда в навколишньому світі. Сьогодні успішним може бути фізично, духовно і морально здорова людина, впевнений в собі, здатний до професійно-творчої самореалізації, самостійного прийняття рішень [1].

Тому однією 3 основних проблем загальноосвітньої школи на сьогоднішній день $є$ збереження і зміцнення здоров'я учнів, формування основ здорового способу життя. Відповідальність за вирішення даної проблеми багато в чому лягає на педагогів 3 фізичної культури, в зв'язку з чим актуалізується завдання розвитку індивідуального педагогічної майстерності вчителя, стилю його професійної діяльності як певної стратегії досягнення мети. У свою чергу, професійний стиль залежить від суб'єктивних цінностей, орієнтацій і домінуючих мотивів, рівня компетентності та готовності до самореалізації, і визначається внутрішньою логікою та змістом навчального предмета. Саме рівень сфор- ванности професійних компетентностей i стильова спрямованість майбутнього вчителя визначають продуктивність його педагогічної діяльності $[1 ; 2]$.

Даючи загальну попередню оцінку ступеня наукової розробленості проблеми дослідження, необхідно відзначити, що до теперішнього часу розкрито лише його окремі аспекти, зокрема виділені стилі навчальної діяль ності, описані їх типи, представлена характеристика і т.д. Разом 3 тим, 3 наукових позицій проблема вивченості факторів і педагогічних умов, що сприяють формуванню професійного стилю 3 урахуванням специфіки предметної діяльності, на наш погляд, вивчена недостатньо.

Аналіз останніх досліджень і публікацій. Як показує аналіз останніх досліджень і публікацій, важливими особистісними і професійно-значущими характеристиками для вчителя фізичної культури виступають його мобільність, швидкість і правильність прийняття рішень, успішність міжособистісної взаємодії $[3 ; 6 ; 7]$. У цьому контексті розробка цілісної концепції розвитку особистості майбутнього фахівця, стилю його професійної діяльності як новоутворення, що виражає смислові переваги суб'єктної активності, спрямованість спортивних інтересів і форм спілкування з учнями, є однією 3 головних у підготовці вчителя фізичної культури [4].

Крім того, в завдання педагогічного вузу входить організація роботи по формуванню фахівця, який розуміє зміст і специфіку фізичної культури як соціокультурного феномену, що передбачає переоріентацію освітнього процесу на якісні зміни цілей і завдань підготовки, орієнтацію на технологізації цього процесу $[2 ; 5]$.

Мета статті - дослідження особливостей формування стилю професійної діяльності майбутнього вчителя фізичної культури. 
Виклад основного матеріалу. 3 метою конкретизації поняття «стиль професійної діяльності» проведено аналіз психолого-педагогічних уявлень про індивідуальність і індивідуальному стилі. Незважаючи на відмінності в інтерпретації цих понять, спільним $€$ те, що індивідуальність розглядається як «безліч одиничних особливостей і специфічних рис і якостей, що призводять людини до його неповторності, оригінальності, унікальності».

Власний педагогічний досвід та аналіз наукової літератури, присвяченій даній проблемі показав, що індивідуальне своєрідність проявляється в способі життя людини, його професійної діяльності, спілкуванні, стилі самореалізації. Для складання цілісної характеристики індивідуальності необхідний облік всіх iï аспектів - від интра (тобто. внутрішньої) індивідуальної мінливості до групового статусу; від біологічних характеристик людини як організму до змістовного аналізу відмінностей у внутрішньому світі особистості, так як індивідуальність людини - це певна система багатовимірних і багаторівневих зв'язків, що об'єднує чинники і умови становлення особистості [1].

В результаті вивчення та узагальнення існуючих поглядів нами виділено поняття «стиль» як спосіб прояву індивідуальності, що обумовлює форму відносин, поведінки і діяльності. Індивідуальний стиль при цьому визначається по-різному: як особистісні позиції; як проекція в світ глибинної унікальною сутності людини; як спосіб самовиявлення творчої спонтанної індивідуальності; як певне поєднання методів і прийомів прояви людини в діяльності i спілкуванні; як процесуальна характеристика поведінки, обумовленого особливостями лічностносмислового поля суб'єкта.

Ми розглядаємо стиль професійної діяльності як суб'єктна властивість, як розвивається, динамічну зв'язок професійних і індивідуально-особистісних характеристик, яка виявляється в здатності особистості вибирати певну систему взаємопов'язаних доцільних способів дій для досягнення результатів. У свою чергу, стиль професійної діяльності вчителя - це певна стратегія досягнення мети, опосередкована внутрішньою логікою і змістом предмета, суб'єктивними ціннісними орієнтаціями і домінуючими мотивами.

Було виявлено, що стиль професійної діяльності залежить як від індивідуальних особливостей особистості, так і від специфіки професійних компонентів і рівня сформованості компетенцій, які ми розглядаємо як готовність вчителя до вирішення професійних завдань.

Виявлені залежності дозволили виділити особливості професійної діяльності вчителя фізичної культури, які обумовлені цільовими установками і змістом предмета «Фізична культура».

Успішність здійснення педагогічної діяльності передбачає використання стилю професійної діяльності (предметно-Національні, предметноімпровізаційного) відповідно до віку учнів та предметної підготовленості. Так зі школярами початкових класів і зі спортсменами груп початкової підготовки найбільш ефективним професійним стилем буде предметно-раціональний, 3 огляду на те, що у дітей даної вікової групи ще не досить знань і умінь предмета для самоорганізації і рівень збудження превалює над гальмуванням, 
що створює труднощі в організації і проведенні навчання. 3 віком стильова спрямованість вчителя зміщується до предметно-імпровізаційного. Практика показує, що найбільш успішний вчитель фізичної культури той, який може створити умови, що дають можливість учням самоорганізуватися, самовиразитися в фізкультурної діяльності, організувати навчальний процес 3 урахуванням фізіологічних, фізичних, функціональних і психологічних особливостей учнів.

У структуру професійної діяльності вчителя фізичної культури входить взаємопов'язаний комплекс компонентів:

- професійно-когнітивний характеризується знанням вікових i психологічних особливостей розвитку школяра в контексті формування фізичної культури особистості;

- предметно-інструментальний характеризується знанням принципів гуманної педагогіки і проявляється в умінні вибирати i використовувати сучасні оздоровчі технології, виділити мета, розроблялися зміст конкретних занять, володіння педагогічною рефлексією;

- здоровьеформирующих проявляється в конструктивних уміннях створювати i коректувати здоровьесохранную освітнє середовище; вміння направляти особистісний розвиток школяра; використовувати індивідуальний підхід;

- предметно-комунікативний має на увазі розвинену культуру спілкування (мовну, педагогічну і т.д.), здатність до швидкого реагування на виникає ситуацію, володіння різними способами взаємодії;

- предметно-креативний виражається в розвиненому творчому мисленні, моторно-творчому самовираженні і характеризується здатністю знаходити i використовувати різні варіанти вирішення педагогічних завдань; здатність вільно переходити від однієї проблеми до іншої; приймати ефективні, нестандартні, неординарні рішення.

Успішність здійснення педагогічної діяльності також передбачає оволодіння необхідними професійними компетенціями. Причому, ми виділяємо ключові спеціально-професійні компетенції вчителя фізичної культури (когнітивна, предметно-інструментальна, здоровьеформирующих, комунікативна, креативна), спрямовані на реалізацію визначених нами компонентів.

Грунтуючись на визначенні терміна «формування» (дозрівання, розвиток особистості, зміна, вдосконалення динамічної функціональної структури особистості), ми сформулювали власне розуміння термінологічного поєднання «формування стилю професійної діяльності», під яким на увазі вплив зовнішніх впливів виховання, навчання, соціального середовища, що розглядається як процес спеціально спрямованого збагачення внутрішнього світу.

Ми встановили, що процес формування професійного стилю включає в себе технологію, спрямовану на освоєння системи знань про особливості компетенцій, притаманних професії вчителя фізичної культури; моделювання 
досвіду їх прояви в рішенні педагогічних задач і безпосередній навчальній практиці; розширення мотиваційно-ціннісної сфери і досвіду самопізнання, заснованого на можливості вибору стилю самовияву.

Під технологією ми розуміємо алгоритмизировать модель педагогічного процесу, заснованого на положеннях методологічні, системності, керованості, повторності, ефективності, модульності і спрямованого на формування стилю професійної діяльності включає в себе сукупність взаємопов'язаних елементів, таких як:

- аналіз майбутньої і майбутньої діяльності, спрямованої на формування професійного стилю;

- визначення структурних компонентів i ключових професійних компетенцій, змісту і обсягу навчального матеріалу, спрямованого на їх формування, вираженого в годинах;

- розподіл навчального матеріалу з дисциплін спеціалізації, модулів, семестрах і років навчання;

- розробка критеріїв, підготовка пакету методик для оцінки рівня сформованості професійного стилю, комплексність і варіативність його змісту;

- створення системи оцінки якості засвоєння матеріалу, що відображає ступінь сформованості стилю професійної діяльності, іiі використання в навчальній діяльності;

- розробка структури і змісту занять;

- науково-методичне забезпечення даного процесу;

- створення системи корекції змісту матеріалу, заснованого на «зворотного зв'язку».

Успішність здійснення педагогічної діяльності передбачає оволодіння необхідними професійними компетенціями, що дозволяють реалізовувати структурні компоненти діяльності вчителя фізичної культури.

Професійно-когнітивний компонент - когнітивна компетенція характеризується знанням вікових і психологічних особливостей розвитку школяра в контексті формування фізичної культури особистості.

Предметно-інструментальний компонент - предметно-інструментальна компетенція визначається знанням принципів гуманної педагогіки i проявляється в умінні вибирати i використовувати сучасні оздоровчі технології, виділити мета, розробляти зміст конкретних занять, володіння педагогічною рефлексією.

Здоров'яформуючий компонент - здоровёяформуюча компетенція проявляється в конструктивних уміннях створювати i коректувати здоровьесохранную освітнє середовище; вміння направляти особистісний розвиток школяра; використовувати індивідуальний підхід.

Професійно комунікативний компонент - комунікативна компетенція передбачає розвинену культуру спілкування (мовну, педагогічну і т.д.), здатність до швидкого реагування на виникає ситуацію, володіння різними способами взаємодії. 
Професійно-креативний компонент - креативна компетенція виражається в розвиненому творчому мисленні, моторно-творчому самовираженні i характеризується здатністю знаходити і використовувати різні варіанти вирішення педагогічних завдань; здатність вільно переходити від однієї проблеми до іншої; приймати ефективні, нестандартні, неординарні рішення.

Висновки. Розглянувши різноманітні психологічні та педагогічні підходи до розуміння феномену «індивідуальний і професійний стиль педагогічної діяльності», з огляду на специфіку професійної діяльності вчителя фізичної культури, були віднесені до області стилю такі характеристики педагогічної діяльності, як висока вмотивованість самостійної творчої діяльності; індивідуальне особливе розуміння аспектів педагогічної роботи; ступінь внесення в свою роботу особистісного начала; прагнення до саморозвитку та самовдосконалення в професійній діяльності; задоволення потреби в професійній самореалізації та ін.

Успішність здійснення педагогічної діяльності передбачає оволодіння необхідними професійними компетенціями, що дозволяють реалізовувати структурні компоненти діяльності вчителя фізичної культури.

Професійно-когнітивний компонент - когнітивна компетенція характеризується знанням вікових і психологічних особливостей розвитку школяра в контексті формування фізичної культури особистості.

Предметно-інструментальний компонент - предметно-інструментальна компетенція визначається знанням принципів гуманної педагогіки i проявляється в умінні вибирати i використовувати сучасні оздоровчі технології, виділити мета, розробляти зміст конкретних занять, володіння педагогічною рефлексією.

Здоров'яформуючий компонент - здоровёяформуюча компетенція проявляється в конструктивних уміннях створювати i коректувати здоровьесохранную освітнє середовище; вміння направляти особистісний розвиток школяра; використовувати індивідуальний підхід.

Професійно комунікативний компонент - комунікативна компетенція передбачає розвинену культуру спілкування (мовну, педагогічну i т.д.), здатність до швидкого реагування на виникає ситуацію, володіння різними способами взаємодії.

Професійно-креативний компонент - креативна компетенція виражається в розвиненому творчому мисленні, моторно-творчому самовираженні i характеризується здатністю знаходити і використовувати різні варіанти вирішення педагогічних завдань; здатність вільно переходити від однієї проблеми до іншої; приймати ефективні, нестандартні, неординарні рішення.

\section{Jimepamypa:}

1. Dmitriieva, N. Ensuring the acquisition of professional skills and professional experience during the practical training of professional junior bachelors in physical culture and sports // Engineering and Educational Technologies. № 9 (2), 2021, pp. 42-52. doi: https://doi.org/ 10.30929/2307-9770.2021.09.02.04 
2. Dmitriieva, N. Psychological training of future specialists in physical culture and sports for the activities of a sports coach in higher education institutions // Engineering and Educational Technologies. № 9 (1), 2021, pp. 90-101. doi: https://doi.org/10.30929/2307-9770.2021.09.01.08

3. Salmi, H., Thuneberg, H. The role of self-determination in informal and formal science learning contexts // Learning Environments Research. № 22(1), 2019, pp. 43-63.

4. Tolgfors, B. Different versions of assessmentforlearning in the subject of physical education. Phys Educ Sport Pedagogy. № 23(3), 2018, pp. 311-27. https://doi.org/10.1080/17408989.2018.1429589

5. Vallett, D. B., Lamb, R., Annetta, L. After-School and Informal STEM Projects: The effect of participant self-selection // Journal of Science Education and Technology. № 27(3), 2018, pp. 248-255. https://doi.org/10.1007/s10956-017-9721-1

6. Vennix, J., den Brok, P., Taconis, R. Do outreach activities in secondary STEM education motivate students and improve their attitudes towards STEM? // International Journal of Science Education. № 40(11), 2018, pp. 1263-1283 https://doi.org/10.1080/09500693.2018.1473659

7. Zhou, L., Ntoumanis, N., Thogersen-Ntoumani, C. Effects of perceived autonomy support from social agents on motivation and engagement of Chinese primary school students: Psychological need satisfaction as mediator // Contemporary Educational Psychology. № 58, 2019, pp. 323-330 https://doi.org/10.1016/j.cedpsych.2019.05.001

\section{References:}

1. Dmitriieva N. (2021). Ensuring the acquisition of professional skills and professional experience during the practical training of professional junior bachelors in physical culture and sports. Engineering and Educational Technologies, 9 (2), 42-52. doi: https://doi.org/10.30929/2307-9770.2021.09.02.04

2. Dmitriieva, N. (2021). Psychological training of future specialists in physical culture and sports for the activities of a sports coach in higher education institutions. Engineering and Educational Technologies, 9 (1), 90-101. doi: https://doi.org/10.30929/2307-9770.2021.09.01.08

3. Salmi, H., Thuneberg, H. (2019). The role of self-determination in informal and formal science learning contexts. Learning Environments Research, 22(1), 43-63.

4. Tolgfors, B. (2018). Different versions of assessmentforlearning in the subject of physical education. Phys Educ Sport Pedagogy, 23(3):311-27. https://doi.org/10.1080/17408989. 2018.1429589

5. Vallett, D. B., Lamb, R., Annetta, L. (2018). After-School and Informal STEM Projects: The effect of participant self-selection. Journal of Science Education and Technology, 27(3), 248255 https://doi.org/10.1007/s10956-017-9721-1

6. Vennix, J., den Brok, P., Taconis, R. (2018). Do outreach activities in secondary STEM education motivate students and improve their attitudes towards STEM? International Journal of Science Education, 40(11), 1263-1283 https://doi.org/10.1080/09500693.2018.1473659

7. Zhou, L., Ntoumanis, N., Thogersen-Ntoumani, C. (2019) Effects of perceived autonomy support from social agents on motivation and engagement of Chinese primary school students: Psychological need satisfaction as mediator. Contemporary Educational Psychology, 58, 323-330 https://doi.org/10.1016/j.cedpsych.2019.05.001 